\title{
Predicting intraoperative pain in emergency endodontic patients: clinical study
}

\author{
Olga YÜCEL(a) \\ Mügem Aslı EKICI(a) \\ Ozlem ILK ${ }^{(b)}$ \\ Mustafa Necmi ILHAN(c) \\ Guven KAYAOGLU(a)
}

(a) Gazi University, Faculty of Dentistry,

Department of Endodontics, Ankara, Turkey

(b)Middle East Technical University,

Department of Statistics, Ankara, Turkey

(c) Gazi University, Faculty of Medicine, Department of Public Health, Ankara, Turkey

Declaration of Interests: The authors certify that they have no commercial or associative interest that represents a conflict of interest in connection with the manuscript.

\section{Corresponding Author:}

Guven Kayaoglu

E-mail:guvenkayaoglu@gmail.com

Submitted: October 29, 2017

Accepted for publication: January 31, 2018

Last revision: March 16, 2018

\begin{abstract}
This prospective observational study sought to investigate the incidence of intraoperative pain (IOP) among emergency endodontic patients and to construct an IOP prediction model that includes preoperative pain level (PPL). All patients who underwent emergency endodontic treatment at Gazi University, Ankara, Turkey, during the spring term of 2016 were considered for inclusion in the study. Demographic and clinical variables and PPL were recorded. Local anesthesia was provided to all patients before beginning routine endodontic treatment. IOP was defined as the condition of requiring supplementary anesthesia before the working length was established and exhibiting persistent moderate or severe pain despite supplementary anesthesia. Data from $85 \%$ and $15 \%$ of 435 patients (178 men, 257 women; mean age: 35 years) were used to develop predictive models by multiple logistic regression analysis and to test external validity of the models, respectively. Two multiple logistic regression models achieved good model fits. Model 1 included age, pulpal diagnosis, and arc $(p<0.05)$. In addition to these variables, Model 2 included periapical diagnosis and PPL $(\mathrm{p}<0.15)$. Models 1 and 2 showed accuracies of 0.76 and 0.75 , sensitivities of 0.74 and 0.77 , and specificities of 0.76 and 0.74 , respectively for the modeling data (internal validity), and accuracies of 0.82 and 0.80 , sensitivities of 0.83 and 0.67 , and specificities of 0.81 and 0.81 , respectively for the control data (external validity). The IOP incidence was $10.3 \%$. IOP in patients undergoing emergency endodontic treatment can be successfully predicted by using models that account for demographic and clinical variables, including PPL.
\end{abstract}

Keywords: Anesthesia, Dental; Emergency Treatment; Endodontics; Forecasting; Measurement.

\section{Introduction}

Intraoperative pain (IOP) during endodontic treatment is a difficult condition for both the patient and the dentist, and may occur despite administration of adequate local anesthesia. IOP may be due to the use of defective solutions, anatomic variations, and patient anxiety. ${ }^{1}$ Moreover, inflammation-related changes, including an increased responsiveness to stimuli, lowered pain threshold, and neuronal phenotypic changes due to peripheral and central sensitization, ${ }^{2,3}$ can cause IOP during endodontic treatment. A few clinical studies have investigated the relationship between demographic and clinical 
variables and the occurrence of IOP during endodontic treatment. These studies generally concluded that mandibular molar teeth with pulpal inflammation have the greatest risk of developing IOP., ${ }^{4,5}$

Teeth that are sensitive before treatment are difficult to anesthetize. ${ }^{6}$ One recent study identified the "presence of preoperative pain within the previous 24 hours" as a predictive factor for IOP in a multiple logistic regression model. ${ }^{7}$ Another recent study, categorizing patients according to their preoperative pain level (PPL), found that IOP during endodontic treatment increased with an increase in the severity of the PPL. ${ }^{8}$ Therefore, PPL may be an important variable in predictive models of IOP.

Endodontic pain is one of the most common reasons that patients seek dental or medical emergency services. ${ }^{9,10}$ Clinicians should sympathize with the distressed patient and seek to alleviate the pain. However, alleviation of preoperative pain in symptomatic endodontic patients through anesthesia does not guarantee a completely pain-free treatment session, as pain may be provoked during treatment. ${ }^{11}$ The use of models that can predict whether an emergency endodontic patient will experience IOP would allow the clinician to take necessary precautions to prevent additional pain. Therefore, the aims of this study were to assess the incidence of IOP among emergency endodontic patients receiving treatment at a dental faculty clinic and to construct a model from demographic and clinical factors, including PPL, for predicting the probability of IOP.

\section{Methodology}

This study was approved by the Ethical Review Board of Keçiören Training and Research Hospital, Ankara (2012-KAEK-15/1040; Dec 09, 2015).

\section{Radiographic calibration of observers}

Three observers (O.Y., M.E., and G.K.) were calibrated regarding their application of the periapical index (PAI; visual material provided by Dr. Dag Ørstavik $)^{12}$ before any clinical data were collected. Cohen's kappa ( $\kappa)$ values were calculated to compare observers' scores to reference scores. $\kappa$ values ranged from 0.74 to 0.96 , indicating substantial to almost- perfect agreement. ${ }^{13}$ Applying the PAI, observers independently examined 95 digital radiographs obtained on 3 consecutive clinical days and classified periapical status as "healthy" (scores 1 and 2) or "diseased" (scores 3 to 5). Fleiss' $\kappa$ value of interobserver agreement was 0.79 (> 0.75, indicating excellent agreement beyond chance). ${ }^{14}$ At least 6 weeks after the first rating, observers performed a second rating of 50 randomly selected radiographs. Cohen's $\kappa$ values of intraobserver agreement ranged from 0.80 to 0.96 , indicating substantial to almost-perfect agreement.

\section{Terminology and standards}

Cases of endodontic emergency were classified according to Wolcott et al. ${ }^{15}$ Established diagnostic terminologies were used to define pulpal status (normal pulp, reversible pulpitis, irreversible pulpitis, and pulp necrosis) and periapical status (normal apical tissue, symptomatic apical periodontitis, asymptomatic apical periodontitis, acute apical abscess, and chronic apical abscess). ${ }^{16}$ Pulp was considered vital if hemorrhage was observed during access to the pulp chamber or root canal. ${ }^{17}$ General health status was recorded as "good" or "not good", 18 with the latter category including patients with allergies, chronic infectious diseases, or systemic conditions.

Anesthesia was administered in accordance with guidelines of the Department of Endodontics of the Faculty of Dentistry at Gazi University. ${ }^{19}$ All maxillary teeth and mandibular incisors were anesthetized with local infiltration anesthesia (1-2 mL). Remaining mandibular teeth were anesthetized with regional anesthesia (inferior alveolar nerve block or mental nerve block; $1.5-2 \mathrm{~mL})$. Supplementary buccal (1 mL) and lingual $(1 \mathrm{~mL})$ or palatinal $(0.2 \mathrm{~mL})$ local infiltration anesthesia was administered as needed. If supplemental anesthesia was insufficient, then intraligamentary and intrapulpal anesthesia was applied. Patients quantified pain levels on the 170-mm Heft-Parker visual analog scale (VAS), which was divided into 4 categories: no pain $(0 \mathrm{~mm})$, mild pain $(1-54 \mathrm{~mm})$, moderate pain $(55-113 \mathrm{~mm})$, and severe pain $(\geq 114 \mathrm{~mm}) \cdot{ }^{20}$

\section{Clinical setting and patients}

The study was carried out at the Dental Student Training Clinic of the Department of Endodontics of 
the Faculty of Dentistry at Gazi University during the spring term of 2016 (January 18-May 13; 85 clinical days). Most emergency treatments were carried out by residents, although a few patients were treated by dental students under the supervision of clinical instructors. Hereinafter, residents and dental students are cited as "operators".

\section{Patient inclusion and exclusion criteria}

This study included adult patients (age $\geq 18$ years) who required nonscheduled, emergency primary root canal treatment and provided written informed consent for participation. Patients were excluded from the study if they had traumatic dental injury, endoperio lesions, multiple teeth requiring root canal treatment with no ability to differentiate the source of pain, or a history of previous endodontic treatment. Patients who were experiencing endodontic flare-up or facial pain with a nonodontogenic origin were excluded, as were patients whose tooth to be treated was already anesthetized before admission. Figure 1 shows the flowchart of patient inclusion in this study. A total of 9461 patients were admitted to the clinic for endodontic treatment. We excluded data from 9026 patients who failed to meet the study criteria. The final dataset comprised data from 435 patients.

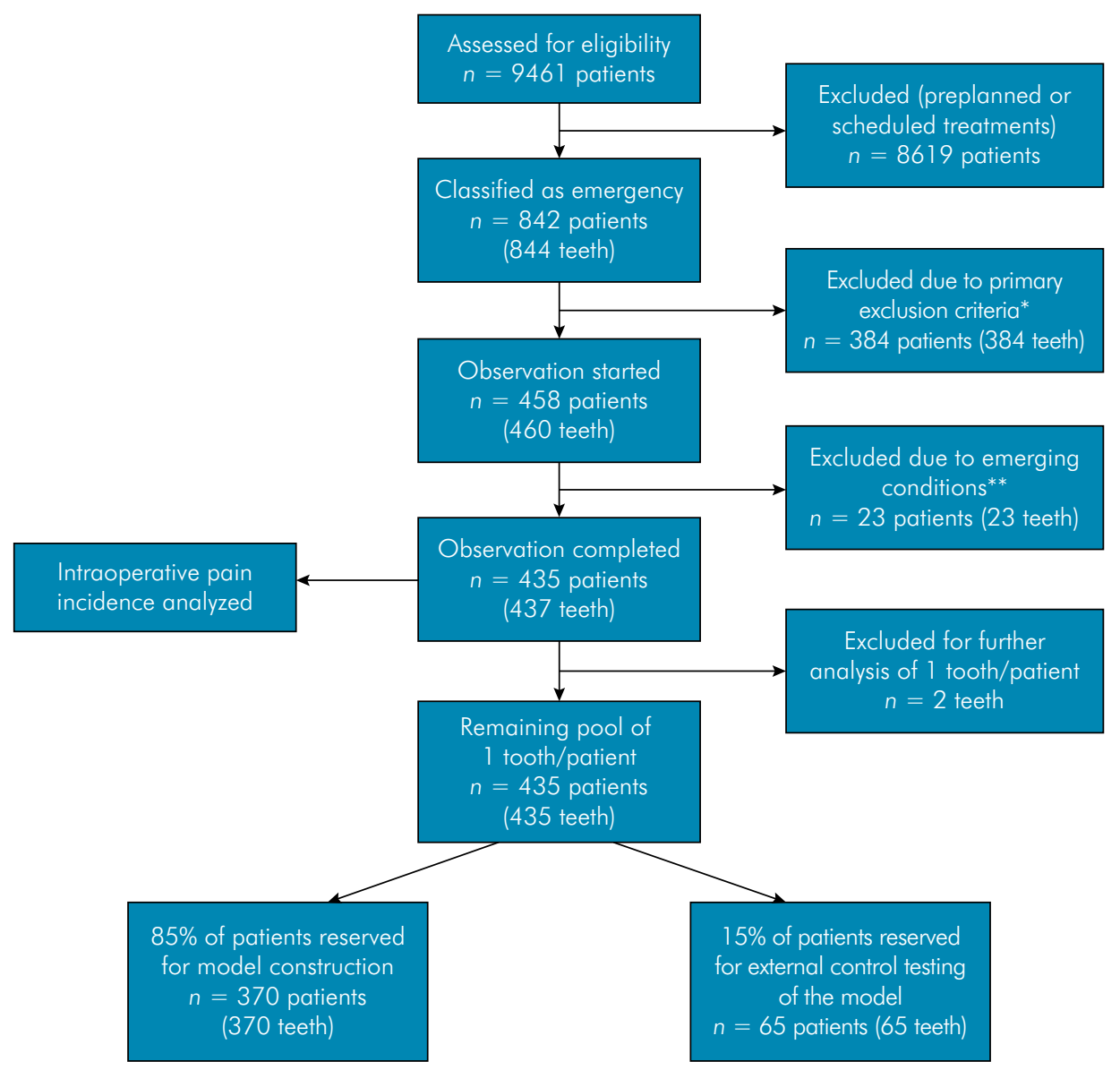

\footnotetext{
* Reasons: age $<18$ years $(n=46)$, unable to communicate $(n=7)$, refused to give informed consent/rejected treatment $(n=2)$, previous endodontic treatment $(n=61)$, patient confused the source of pain $(n=36)$, tooth was already anesthetized for restorative or prosthetic reasons $(n=73)$, endodontic treatment not indicated $(n=103)$, endodontic flare-up $(n=42)$, dental/dentoalveolar traumatic injury $(n=3)$, endo-perio lesion $(n=2)$, nonodontogenic pain $(n=1)$, required medical sedation $(n=1)$, patient postponed treatment $(n=6)$, and unregistered $(n=1)$. ** Reasons: patient or operator did not inform of pain although it existed $(n=7)$, lack of definite pulpal diagnosis/partial necrosis $(n=4)$, pain not originating from pulp $(n=3)$, supplementary local infiltration anesthesia could not be administered due to swelling $(n=3)$ or due to patient's medical condition $(n=1)$, and observation protocol fault $(n=5)$.
}

Figure 1. Flowchart of the study. 


\section{Study protocol}

At least one investigator was present in the clinic throughout the study period. Residents performed all clinical examinations. Investigators participated in the examination of patients and the interpretation of radiographs. Examinations were done via routine methods (electric pulp test, thermal tests, percussion, etc). The following demographic and clinical variables were recorded: age (years), sex (male/female), health status (good/not good), whether pain was present within the previous 24 hours (yes/no), whether the patient had taken analgesic for toothache within the previous 24 hours (yes/no/yes, but for other reasons), and pulpal and periapical diagnoses.

Before receiving local anesthesia, the patient rated their PPL on the VAS. A resident or investigator administered anesthetic solution ( $4 \%$ articaine hydrochloride with 1:200,000 epinephrine in a 2-mL ampule; Maxicaine, VEM, Ankara, Turkey) using a 2-mL dental syringe and 27G needle. If the patient had cardiovascular or thyroid problems, then anesthesia without epinephrine was used ( $3 \%$ mepivacaine hydrochloride in a 2-mL ampule; Safecaine, VEM). After injection and confirmation of anesthesia, the patient was asked to inform the operator if pain was felt during treatment. Any incidence of pain during treatment was recorded by the operator.

Patients were asked to rate their pain as soon as the working length $(\mathrm{WL})$ was established (intraoperative VAS). If a patient complained of pain before the WL was established, then supplementary local infiltration anesthesia was administered. In this case, the patient was asked to rate the pain after supplementary anesthesia. If pain persisted, then the observation was terminated, and the patient was asked to rate the pain. Intraligamentary and intrapulpal anesthesia was administered, and routine treatment was continued. A VAS score of 0-54 indicated successful anesthesia (coded as 0 ). A VAS score $>54$ indicated unsuccessful anesthesia (coded as 1; patient registered as having IOP).

\section{Statistical analysis}

Incidence of IOP was calculated with consideration of all clinical data. For logistic regression analyses, only 1 randomly chosen tooth per patient was considered.

Multiple logistic regression models were constructed and the external validity of the models was tested by using data from $85 \%$ and $15 \%$ of patients, respectively. Patients were randomly selected for either group by using the "sample" function in R3.3.1. ${ }^{21}$ Model validity was tested by calculating the correct classification rate (accuracy), sensitivity, and specificity of the models for predicting presence of IOP. Accuracy was calculated as [(True Positive (TP) + True Negative (TN)) / (TP + TN + False Positive (FP) + False Negative (FN))]. Sensitivity was calculated as [TP / (TP + FN)]. Specificity was calculated as [TN / (TN + FP)].

The entry inquiring whether the patient had "taken analgesic within the previous 24 hours" was methodological and was not included in model construction. A p-value of 0.05 or 0.15 was considered statistically significant. Statistical analyses were performed in R 3.3.1. ${ }^{21}$

\section{Results}

\section{Descriptive profile and incidence of IOP}

The final dataset of the 435 patients included 178 men (179 teeth; mean age \pm standard deviation: 34.7 \pm 14.2 years; range: $18-89$ years) and 257 women (258 teeth; mean age \pm standard deviation: $35.7 \pm 13.1$ years; range: $18-70$ years). A single tooth was treated in all cases except for 2 patients who required treatment of 2 teeth at different times.

Supplementary local infiltration anesthesia was administered in 178 cases ( $40.7 \%$ of 437 teeth) and was successful in 133 cases. Thus, the incidence of IOP was $10.3 \%$ (45/437 patients). Numbers of cases of IOP developing from each PPL stratum were as follows: none (5/51), mild (10/141), moderate (21/157) and severe (9/88) PPL. Table 1 reports the distributions of IOP cases according to tooth type and dental arc.

\section{Univariate analyses}

One tooth was randomly selected from each patient for subsequent analyses. Regarding the methodological question "Have you taken analgesic for toothache within the previous 24 hours?", $27.8 \%$ of patients (121/435) responded "No", 71.7\% (312/435) responded "Yes", and 0.5\% (2/435) responded "Yes, but for other reasons". Among patients giving these responses, IOP (VAS code 1) was found in 9 (7.4\%), 36 (11.5\%), and $0(0 \%)$ patients, respectively, with no significant 
difference in IOP incidence between "No" versus "Yes" respondents ( $\chi^{2}$ test, $\left.\mathrm{p}=0.2805\right)$. Only 3 patients answered "No" to the question "Was pain present in the previous 24 hours?" Therefore, this variable was not included in further analyses. Univariate analyses identified age, pulpal diagnosis, periapical diagnosis, tooth type, and arc as significant factors influencing IOP $(p<0.05$; Table 2$)$. For the critical analysis of the

Table 1. Descriptive cross table showing rates of intraoperative pain (VAS Code: 1) according to tooth type and dental arc.

\begin{tabular}{lcccr}
\hline Dental Arc & Incisor & Canine & Premolar & Molar \\
Maxilla & $0 / 34(0)$ & $0 / 11(0)$ & $6 / 66(9.09)$ & $3 / 122(2.46)$ \\
Mandible & $0 / 2(0)$ & $1 / 13(7.69)$ & $1 / 43(2.33)$ & $34 / 146(23.29)$ \\
\hline
\end{tabular}

*Data represent n (\%) among 437 cases.

Table 2. Results of univariate logistic regression analyses of modeling data $(n=370)$.

\begin{tabular}{|c|c|c|c|c|}
\hline Variable & VAS: $0 ; n(\%)$ & VAS: 1 ; n (\%) & OR $(95 \% \mathrm{Cl})$ & $\mathrm{p}$-value \\
\hline Age (continuous data) & & & $0.97(0.94-0.99)$ & 0.0212 \\
\hline \multicolumn{5}{|l|}{ Sex } \\
\hline Male $(n=151)$ & $136(90.07)$ & $15(9.93)$ & 1 & \\
\hline Female $(n=219)$ & 195 (89.04) & $24(10.96)$ & $1.12(0.56-2.21)$ & 0.7520 \\
\hline \multicolumn{5}{|l|}{ Health status } \\
\hline Good $(n=260)$ & 232 (89.23) & $28(10.77)$ & 1 & \\
\hline Not good $(n=110)$ & $99(90.00)$ & $11(10.00)$ & $0.92(0.44-1.92)$ & 0.8260 \\
\hline \multicolumn{5}{|l|}{ Tooth type } \\
\hline Molar $(n=223)$ & $192(86.10)$ & $31(13.90)$ & 1 & \\
\hline Nonmolar $(n=147)$ & 139 (94.56) & $8(5.44)$ & $0.36(0.16-0.80)$ & 0.0123 \\
\hline \multicolumn{5}{|l|}{ Arc } \\
\hline Mandible $(n=180)$ & 149 (82.78) & $31(17.22)$ & 1 & \\
\hline Maxilla $(n=190)$ & 182 (95.79) & $8(4.21)$ & $0.21(0.09-0.47)$ & 0.0002 \\
\hline \multicolumn{5}{|l|}{ Pulpal diagnosis } \\
\hline Irreversible pulpitis ( $\mathrm{n}=270$ ) & 232 (85.93) & $38(14.07)$ & 1 & \\
\hline Necrotic pulp $(n=100)$ & $99(99.00)$ & $1(1.00)$ & $0.06(0.01-0.46)$ & 0.0063 \\
\hline \multicolumn{5}{|l|}{ Periapical diagnosis* } \\
\hline Other $(n=97)$ & $84(86.60)$ & $13(13.40)$ & 1 & \\
\hline Symptomatic apical periodontitis $(n=273$ ) & $247(90.48)$ & $26(9.52)$ & $0.68(0.33-1.38)$ & 0.2880 \\
\hline \multicolumn{5}{|l|}{ Periapical diagnosis* } \\
\hline Other $(n=307)$ & $281(91.53)$ & $26(8.47)$ & 1 & \\
\hline Normal periapex $(n=63)$ & $50(79.37)$ & $13(20.63)$ & $2.81(1.35-5.83)$ & 0.0056 \\
\hline \multicolumn{5}{|l|}{ Anesthetic solution } \\
\hline Articaine $(n=340)$ & $303(89.12)$ & $37(10.88)$ & 1 & \\
\hline Mepivacaine $(\mathrm{n}=30)$ & $28(93.33)$ & $2(6.67)$ & $0.59(0.13-2.56)$ & 0.4760 \\
\hline \multicolumn{5}{|l|}{ PPL } \\
\hline $0-54(n=167)$ & $154(92.22)$ & $13(7.78)$ & 1 & \\
\hline$>54(n=203)$ & $177(87.19)$ & $26(12.81)$ & $1.74(0.86-3.50)$ & 0.1210 \\
\hline
\end{tabular}

*Two separate dummy variables were tested for periapical diagnosis. OR: odds ratio, Cl: confidence interval, PPL: preoperative pain level. 
study, the dataset including the complete question list in the univariate analysis, the distribution of patient's answers to each question, and the clinical records is shown in Supplementary Material (Appendix Spreadsheet 1). (See the file at: http://www.websitem. gazi.edu.tr/site/guvenk/files)

\section{Construction of models 1 and 2}

We performed multiple regression analyses of variables that were significantly associated with pain (VAS code 1) in the univariate analysis. Variables "periapical diagnosis" and "tooth type" were not statistically significant and were excluded from the final attempt. Variables age, pulpal diagnosis, and arc were retained in the model $(\mathrm{p}<0.05)$. From the modeling data ( $n=370 ; 85 \%$ of patients), we developed a strict model with a conventional $p$ value of 0.05 at the entry and retention levels (Model 1, Table 3). Motivated to include PPL in the prediction model, we developed a model that accepted a more tolerant $p$ value (type I error $(\alpha)=15 \%$ ) at the entry and retention levels (Model 2). Upon testing age, pulpal diagnosis, periapical diagnosis, tooth type, arc, and PPL, all variables except tooth type $(p>0.15)$ were retained in the model. Using the modeling data, we developed a flexible model that included PPL (Model 2, Table 3).

Variance inflation factors for the modeling data ranged between 1.0010 and 1.0165 for Model 1, and between 1.0159 and 1.0992 for Model 2. Thus, there was no multicollinearity problem among the predictor variables of both models. ${ }^{22}$ Estimated probabilities of IOP from Model 1 and Model 2 are shown in Figure 2.

\section{Internal and external validity of the models}

Using the Hosmer-Lemeshow goodness-of-fit test with the modeling data ( $85 \%$ of patients) and the external data ( $15 \%$ of patients), we confirmed the good fits of Model 1 ( $p=0.695$ and $p=0.694$, respectively) and Model 2 ( $p=0.603$ and $p=0.852$, respectively). These models provided the probability that a patient would develop IOP. A patient was predicted to have IOP if their probability of pain was higher than a threshold value of 0.125 , which was chosen after testing different threshold values around the IOP incidence of $10 \% .{ }^{22}$ Using this threshold with the modeling data, we obtained efficiencies of 0.76 and 0.75 , sensitivities of 0.74 and 0.77 , specificities of 0.76 and 0.74 , and Akaike Information Criterion (AIC) values of 214.35 and 212.09 for Model 1 and Model 2, respectively. Using the external data, we obtained efficiencies of 0.82 and 0.80 , sensitivities of 0.83 and 0.67 , and specificities of 0.81 and 0.81 for Model 1 and Model 2, respectively. Applications of the two prediction models are presented in Supplementary Material (Appendix Spreadsheet 2). (See the file at: http://www.websitem.gazi.edu.tr/site/guvenk/files)

We also attempted to construct a model similar to Model 2, but using absolute PPL data (numerical, continuous) instead of a dichotomized entry. However, the internal and external validity outputs of that model were inferior to those of Model 2. Therefore, that model is not presented here.

Table 3. Results of predictive multiple logistic regression models 1 and 2 using modeling data $(n=370)$.

\begin{tabular}{|c|c|c|c|c|}
\hline Model (intercept) & Variable (test/reference category) & Coefficient & OR $(95 \% \mathrm{Cl})$ & $\mathrm{p}$-value \\
\hline \multirow{3}{*}{ Model $1(0.20)$} & Age (continuous data) & -0.04 & $0.96(0.93-0.99)$ & 0.0067 \\
\hline & Pulpal diagnosis (necrotic pulp/irreversible pulpitis) & -2.76 & $0.06(0.01-0.47)$ & 0.0072 \\
\hline & Arc (maxilla/mandible) & -1.64 & $0.19(0.08-0.45)$ & 0.0001 \\
\hline \multirow{5}{*}{ Model $2(-0.38)$} & Age (continuous data) & -0.04 & $0.96(0.93-0.99)$ & 0.0063 \\
\hline & Pulpal diagnosis (necrotic pulp/irreversible pulpitis) & -2.45 & $0.09(0.01-0.66)$ & 0.0180 \\
\hline & Periapical diagnosis (normal periapex/others) & 0.93 & $2.52(1.11-5.73)$ & 0.0271 \\
\hline & Arc (maxilla/mandible) & -1.66 & $0.19(0.08-0.44)$ & 0.0001 \\
\hline & PPL (> 54/0-54) & 0.65 & $1.92(0.89-4.18)$ & 0.0983 \\
\hline
\end{tabular}

OR: odds ratio, $\mathrm{Cl}$ : confidence interval, PPL: preoperative pain level. 
Model 1

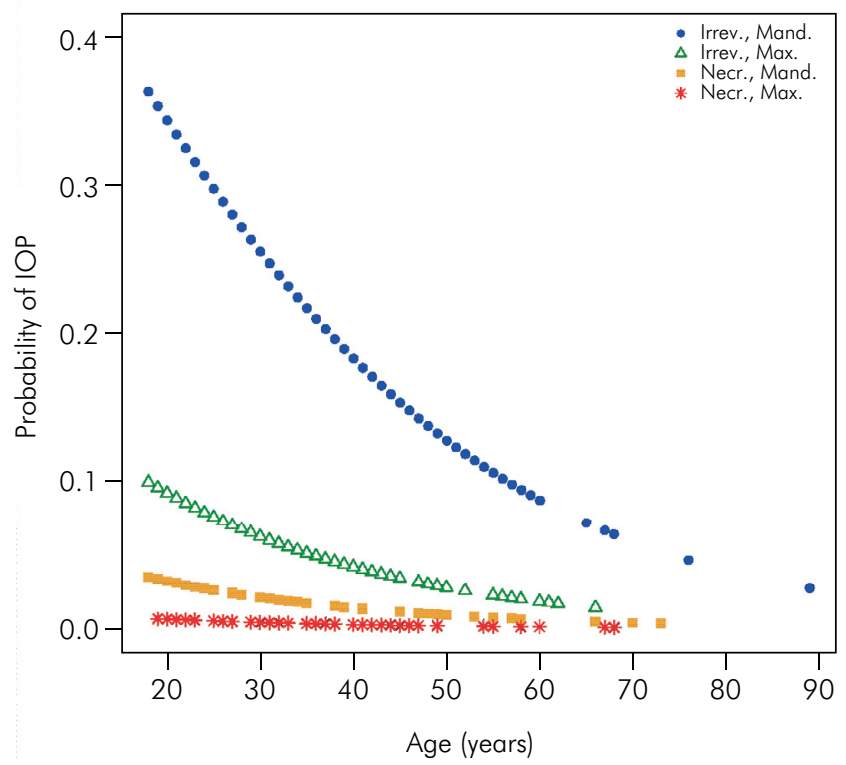

Model 2

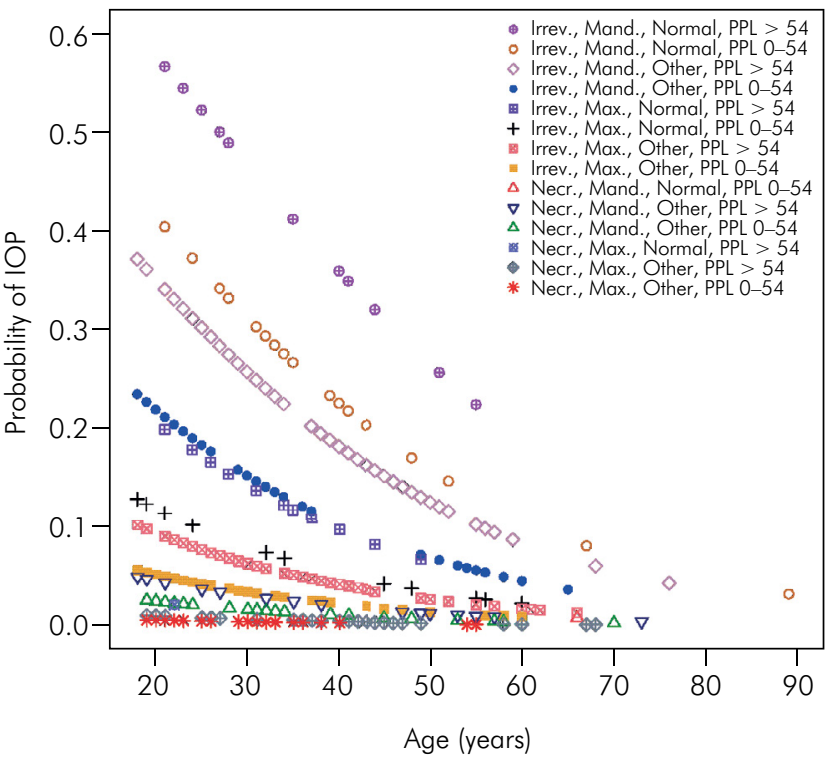

Figure 2. Estimated probabilities of intraoperative pain according to age from Model 1 and Model 2 ( $\mathrm{n}=370$, each model). In Model 2, no case fell into the 'Necr., Max., Normal, PPL 0-54' or 'Necr., Mand., Normal, PPL > 54' categories (Abbreviations; Irrev.: irreversible pulpitis, Necr.: necrotic pulp, Mand.: mandible, Max.: maxilla, Normal: normal periapex, Other: other than normal periapex, PPL: preoperative pain level, IOP: intraoperative pain).

\section{Discussion}

In this study, we developed 2 successful models for predicting IOP in patients undergoing emergency endodontic treatment. The models had good fits for the internal and external data. Pulpal diagnosis (increased risk for irreversible pulpitis), arc (increased risk for mandibular teeth), and age (increased risk for younger age) were common to both models. These factors are already well-known variables associated with IOP. $4,5,7,23$ The novelty in this study was mainly the integration of PPL in the predictive model.

The percentage of patients requiring supplementary local infiltration anesthesia and the IOP incidence in the present study ( $41 \%$ and $10 \%$, respectively) were greater than those reported in a similar study (22\% and $6 \%$, respectively). ${ }^{7}$ This difference can be attributed to the different patient profiles of the 2 studies. The present study comprised emergency patients only, whereas the previous study included nonemergency patients mostly whose appointments were scheduled 1 to 1.5 months earlier. Descriptive data analyses of the studies revealed that the ratio of irreversible pulpitis diagnoses to other diagnoses was greater in the present study (2.6 vs 1.6). This difference partly explains the greater IOP incidence in the present study.

Periapical diagnosis (increased risk for normal periapex) was a covariate in Model 2. An explanation for the association between "normal periapex" and IOP may be that the likelihood of the presence of responsive, inflamed pulp tissue is greater when the periapex is normal, whereas the likelihood of the presence of nonresponsive, necrotic pulp is greater when the periapex has transitioned to the symptomatic status. This finding differs from findings of previous studies, in which the direction of the periapical diagnosis was in favor of "symptomatic apical periodontitis" in cases of IOP., 4,5

A previous study of scheduled endodontic patients found a greater risk of IOP for mepivacaine than for articaine. ${ }^{7}$ In contrast, anesthetic solution was not a determining factor in the present study. In the early stages of pulpal inflammation, the choice of anesthetic solution does not make a difference, and articaine and mepivacaine work similarly. This finding is parallel 
to the findings of two randomized controlled clinical trials performed on emergency endodontic patients with inflamed pulps. ${ }^{24}$

The inclusion of PPL and periapical diagnosis in Model 2 slightly improved the model's quality (lower AIC value) and performance (greater sensitivity for modeling data). The seemingly large difference between the sensitivities of the two models in the testing of the external validity resulted essentially from the dissimilar classification of data from a single patient. Although PPL was previously found to be a predictive factor in a multivariate model for postoperative pain, ${ }^{25}$ the present study extended this finding, showing PPL to be a predictive factor for IOP. PPL was forced into Model 2 by considering a more tolerant $\alpha$ value (0.15) at the entry and retention levels. Although it seems arbitrary to choose an $\alpha$ value greater than the traditional value of 0.05 , researchers have recommended choosing higher alpha values up to 0.30 to avoid overlooking potentially important variables. ${ }^{26,27}$

The clinical use of the developed models may help clinicians in various aspects. For example, communicating the possibility of IOP to the patient prior to treatment would increase the patient's confidence in the operator. A predictive model would give the operator warning and a chance to enact pain-preventative measures, such as preoperative prophylactic medication (nonsteroidal anti-inflammatory drugs, $\mathrm{N}_{2} \mathrm{O} / \mathrm{O}_{2}$ inhalation), ${ }^{11}$ increased anesthetic volume, ${ }^{28}$ or supplementary anesthesia at the beginning of treatment. ${ }^{29}$ Patient schedule times could also be arranged to allow longer treatment periods for patients at risk of IOP.

Concerning the limitations of this study, the models provided here are restricted for use in emergency endodontic patients only and are not suitable for scheduled patients. A model that applies to a general endodontic patient population, comprising mostly scheduled patients, has been described elsewhere. ${ }^{7}$ Another limitation of this study was that patients that had taken analgesics were included in this study. This choice might have introduced some diagnostic error during examination, as analgesics taken before the dental appointment were previously shown to affect endodontic diagnostic testing results. ${ }^{30}$

\section{Conclusions}

In conclusion, the incidence of IOP among emergency endodontic patients during treatment was $10.3 \%$. Two successful predictive models based on demographic and clinical factors were constructed, one of which included PPL as a predictor.

\section{Acknowledgments}

This study constitutes part of the dissertation thesis by Dr. Olga Yücel, entitled "Intraoperative pain incidence and success of prediction models in emergency endodontic patients: prospective observational clinical study", presented at Gazi University in October, 2016. The authors thank Dr. Dag Ørstavik for kindly providing the PAI visual material.

\section{References}

1. Wong MK, Jacobsen PL. Reasons for local anesthesia failures. J Am Dent Assoc. 1992 Jan;123(1):69-73. https://doi.org/10.14219/jada.archive.1992.0004

2. Latremoliere A, Woolf CJ. Central sensitization: a generator of pain hypersensitivity by central neural plasticity. J Pain. 2009 Sep;10(9):895-926. https://doi.org/10.1016/i.jpain.2009.06.012

3. Stein C, Clark JD, Oh U, Vasko MR, Wilcox GL, Overland $A C$ et al. Peripheral mechanisms of pain and analgesia. Brain Res Brain Res Rev. 2009 Apr;60(1):90-113. https://doi.org/10.1016/i.brainresrev.2008.12.017

4. Segura-Egea JJ, Cisneros-Cabello R, Llamas-Carreras $J M$, Velasco-Ortega E. Pain associated with root

canal treatment. Int Endod J. 2009 Jul;42(7):614-20. https://doi.org/10.1111/j.1365-2591.2009.01562.x

5. Martín-González J, Echevarría-Pérez M, Sánchez-Domínguez B, Tarilonte-Delgado ML, Castellanos-Cosano L, López-Frías

FJ et al. Influence of root canal instrumentation and obturation techniques on intra-operative pain during endodontic therapy. Med Oral Patol Oral Cir Bucal. 2012 Sep;17(5):e912-8. https://doi.org/10.4317/medoral.18234

6. Webster S Jr, Drum M, Reader A, Fowler S, Nusstein J, Beck $M$. How Effective Is supplemental intraseptal anesthesia in patients with symptomatic Irreversible pulpitis? J Endod. 2016 Oct;42(10):1453-7. https://doi.org/10.1016/i.joen.2016.07.002 
7. Kayaoglu G, Gürel M, Saricam E, Ilhan MN, Ilk O. Predictive model of intraoperative pain during endodontic treatment: prospective observational clinical study. J Endod. 2016 Jan;42(1):36-41. https://doi.org/10.1016/i.joen.2015.09.021

8. Aggarwal V, Singla M, Subbiya A, Vivekanandhan P, Sharma $V$, Sharma R et al. Effect of preoperative pain on Inferior alveolar nerve block. Anesth Prog. 2015;62(4):135-9. https://doi.org/10.2344/15-00019.1

9. Hong L, Ahmed A, McCunniff M, Liu Y, Cai J, Hoff $G$. Secular trends in hospital emergency department visits for dental care in Kansas City, Missouri, 20012006. Public Health Rep. 2011 Mar-Apr;126(2):210-9. https://doi.org/10.1177/003335491112600212

10. Farmakis ET, Palamidakis FD, Skondra FG, Nikoloudaki $G$, Pantazis N. Emergency care provided in a Greek dental school and analysis of the patients' demographic characteristics: a prospective study. Int Dent J. 2016 Oct;66(5):280-6. https://doi.org/10.1111/idj.12245

11. Parirokh M, Ashouri R, Rekabi AR, Nakhaee $N$, Pardakhti A, Askarifard S et al. The effect of premedication with ibuprofen and indomethacin on the success of inferior alveolar nerve block for teeth with irreversible pulpitis. J Endod. 2010 Sep;36(9):1450-4. https://doi.org/10.1016/j.joen.2010.05.007

12. Orstavik D, Kerekes K, Eriksen HM. The periapical index: a scoring system for radiographic assessment of apical periodontitis. Endod Dent Traumatol. 1986 Feb;2(1):20-34. https://doi.org/10.1111/j.1600-9657.1986.tb00119.x

13. Landis JR, Koch GG. The measurement of observer agreement for categorical data. Biometrics. 1977 Mar;33(1):159-74. https://doi.org/10.2307/2529310

14. Fleiss JL, Levin B, Paik MC. Statistical methods for rates \& proportions. 3rd ed. New Jersey: John Wiley \& Sons; 2003.

15. Wolcott J, Rossman LE, Hasselgren G. Management of endodontic emergencies. In: Hargreaves KM, Cohen S, eds. Cohen's pathways of the pulp. 10th ed. Missouri: Mosby Elsevier; 2011. p. 40-8.

16. American Association of Endodontists - AAE. Glossary of endodontic terms. 9th ed. Chicago: American Association of Endodontists;2016. [cited 2016 Dec 1]. Available from: http:// www.nxtbook.com/nxtbooks/aae/endodonticglossary2016/

17. Harrison JW, Gaumgartner JC, Svec TA. Incidence of pain associated with clinical factors during and after root canal therapy. Part 1. Interappointment pain. J Endod. 1983 Sep;9(9):384-7. https://doi.org/10.1016/S0099-2399(83)80190-3

18. Cheng Y, Cheung GS, Bian Z, Peng B. Incidence and factors associated with endodontic interappointment emergency in a dental teaching hospital in China. J Dent. 2006 Aug;34(7):516-21. https://doi.org/10.1016/i.jdent.2005.12.003
19. Alaçam T, Tınaz A. Dişlerin kök kanal tedavisi için hazırlanması "anestezi ve izolasyon". In: Alaçam T, ed. Endodonti. Ankara: Özyurt Matbaacılık; 2012. p. 263-302.

20. Matthews R, Drum M, Reader A, Nusstein J, Beck M. Articaine for supplemental buccal mandibular infiltration anesthesia in patients with irreversible pulpitis when the inferior alveolar nerve block fails. J Endod. 2009 Mar;35(3):343-6. https://doi.org/10.1016/i.joen.2008.11.025

21. R: The R Project for Statistical Computing. Vienna: The R Foundation; 2016 [cited 2016 Sep 1]. Available from: https://www.r-project.org/

22. Neter J, Kutner MH, Nachtsheim CJ, Wasserman W. Applied linear statistical models. 4th ed. Chicago: McGraw-Hill/ Irwin; 1996.

23. Maggirias J, Locker D. Psychological factors and perceptions of pain associated with dental treatment. Community Dent Oral Epidemiol. 2002 Apr;30(2):151-9. https://doi.org/10.1034/j.1600-0528.2002.300209.x

24. Allegretti CE, Sampaio RM, Horliana AC, Armonia PL, Rocha RG, Tortamano IP. Anesthetic efficacy in Irreversible pulpitis: a randomized clinical trial. Braz Dent J. 2016 Jul-Aug;27(4):381-6. https://doi.org/10.1590/0103-6440201600663

25. Law AS, Nixdorf DR, Aguirre AM, Reams GJ, Tortomasi AJ, Manne BD et al. Predicting severe pain after root canal therapy in the National Dental PBRN. J Dent Res. 2015 Mar;94(3 Suppl):37S-43S. https://doi.org/10.1177/0022034514555144PMID:25355775

26. Hosmer D, Lemeshow S. Applied logistic regression. 2nd ed. New York: John Wiley \& Sons; 2000. https://doi.org/10.1002/0471722146

27. Arias A, Macorra JC, Hidalgo JJ, Azabal M. Predictive models of pain following root canal treatment: a prospective clinical study. Int Endod J. 2013 Aug;46(8):784-93. https://doi.org/10.1111/iej.12059

28. Aggarwal V, Singla M, Miglani S, Kohli S, Singh S. Comparative evaluation of $1.8 \mathrm{~mL}$ and $3.6 \mathrm{~mL}$ of $2 \%$ lidocaine with 1:200,000 epinephrine for inferior alveolar nerve block in patients with irreversible pulpitis: a prospective, randomized single-blind study. J Endod. 2012 Jun;38(6): 753-6. https://doi.org/10.1016/j.joen.2012.02.003

29. Parirokh M, Sadr S, Nakhaee N, Abbott PV, Askarifard S. Efficacy of supplementary buccal infiltrations and intraligamentary injections to inferior alveolar nerve blocks in mandibular first molars with asymptomatic irreversible pulpitis: a randomized controlled trial. Int Endod J. 2014 Oct;47(10):926-33. https://doi.org/10.1111/iej.12236

30. Read JK, McClanahan SB, Khan AA, Lunos S, Bowles WR. Effect of Ibuprofen on masking endodontic diagnosis. J Endod. 2014 Aug;40(8):1058-62. https://doi.org/10.1016/i.joen.2014.05.004 